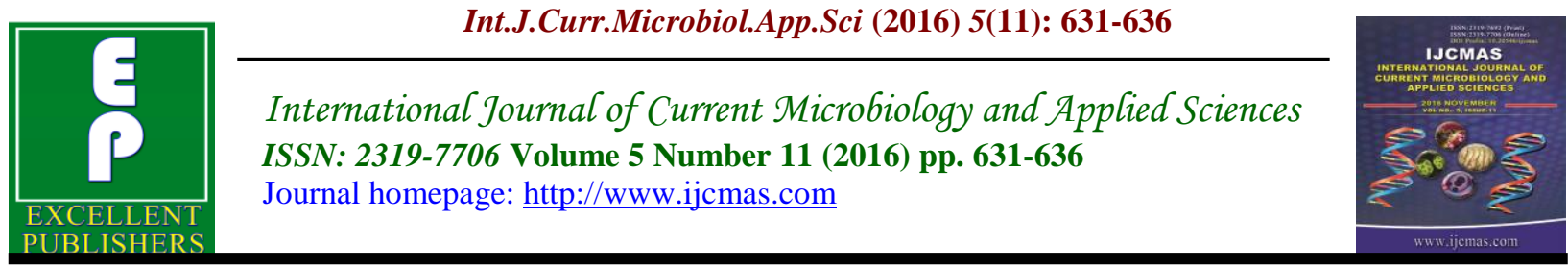

Review Article

http://dx.doi.org/10.20546/ijcmas.2016.511.074

\title{
A Review of Advance Techniques in Diagnosis of Malaria
}

\author{
Rajdeep Paul*, Shyam Sundar Bera and Sumi Nongrum
}

Department of Microbiology, MMIMSR, Mullana, Ambala, Haryana, 133207 India

*Corresponding author

\begin{tabular}{ll}
\hline & A B S T R A C T \\
\cline { 2 - 2 } $\begin{array}{l}\text { Keywords } \\
\begin{array}{l}\text { Plasmodium, } \\
\text { malaria, } \\
\text { female anopheles } \\
\text { diagnosis, } \\
\text { method. }\end{array}\end{array}$ & $\begin{array}{l}\text { Malaria is a major cause of death in tropical and sub-tropical countries, } \\
\text { killing each year over 1 million people globally; 90\% of fatalities occur in } \\
\text { African children. Although effective ways to manage malaria now exist, the } \\
\text { number of malaria cases is still increasing, due to several factors. In this } \\
\text { emergency situation, prompt and effective diagnostic methods are essential } \\
\text { for the management and control of malaria. Traditional methods for } \\
\text { diagnosing malaria remain problematic; therefore, new technologies have } \\
\text { been developed and introduced to overcome the limitations. This review } \\
\text { details the currently available diagnostic methods for malaria. }\end{array}$ \\
\hline $\begin{array}{l}\text { Accepted: } \\
\text { 26 October 2016 } \\
\begin{array}{l}\text { Available Online: } \\
\text { 10 November } 2016\end{array}\end{array}$ \\
\hline
\end{tabular}

\section{Introduction}

Malaria is a mosquito (female anopheles)borne disease caused by a parasite. People with malaria often experience fever, chills, and flu-like illness. Left untreated, they may develop severe complications and die (Centers for Disease Control and Prevention, 2012).

Four Plasmodium species are responsible for human malaria these are $P$. falciparum, $P$. vivax, $P$. ovale and $P$. malariae (Perkins et al., 2011). In 2007, after returning from Malaysia, a Finnish tourist was found to be infected with a fifth Plasmodium species, $P$. knowlesi which usually infects macaques. Over the past few years, hundreds of human cases have been found in Malaysia. The clinical disease caused by $P$. knowlesi appears less severe than $P$. falciparum infection, but more severe than infection with other malaria-causing species. Diagnosis is based both on PCR and microscopy. $P$. knowlesi is currently considered as the fifth species causing malaria in humans (Kantele et al., 2010).

The World Health Organization estimates that half the world's population are at risk of malaria, with 225 million people developing clinical malaria in 2009 (78\% in Africa), and 781,000 deaths $(91 \%$ in Africa, most being children). Malaria remains endemic in 106 countries, and while parasite-based diagnosis is increasing, most suspected cases of malaria are still not properly identified, resulting in over-use of anti malarial drugs 
and poor disease monitoring (Maleria Rapid Diagnostics Test Performance, 2010).

The traditional method of microscopic identification of malaria is time consuming, daunting in poor power setting and requiring a lot of expertise/training. So there are some new techniques in diagnosis of malaria.

\section{Advance techniques in rapid diagnosis of malaria}

\section{Fluorescent microscopy}

It uses readily-prepared and ready to-use slides labelled with an unspecific DNAbinding fluorescent dye (4'-6-Diamidino-2phenylindole (DAPI); emission $443 \mathrm{~nm}$ ) that detects Plasmodium DNA.

Take $0.5 \mathrm{ml}$ well mixed capillary blood and place on the dye labelled area of a slide, place a cover slip, incubate at room temperature for a minute and then observe under the 40x objective under UV light (365 $\mathrm{nm})$.

The presence of bright shiny tiny dots observed under the UV light indicate the presence of malaria parasites (figure 2). To prevent the slides from drying out, they should be kept in a wet chamber (Hassan et al., 2011).

\section{Quantitative Buffy Coat (QBC) Technique}

The principle of this test is based on the fact that Acridine orange (AO) can strongly bind to the deoxyribonucleic acids (DNA) and ribonucleic acids (RNA) and emits green and red fluorescence when excited at 480 nm 16

In the QBC technique, Take approximately 55-65 $\mu \mathrm{l}$ of blood into a capillary tube internally coated with acridine orange, potassium oxalate and fitted with a cap. Insert a plastic float inside the tube and then spin in the QBC microhaematocrit centrifuge at $12000 \mathrm{rpm}$ for 5 minutes. Then mount this tube on a small plastic holder and examine through an ordinary light microscope with customized fluorescence (paralens attachment). Fluorescing parasites are then observed at the red blood cell/white blood cell interface. Approximately 10-20 fields should be examined.

The speed of QBC technique (15 min) in detecting malarial parasites is a definite advantage in laboratories which screen large number of samples. In addition, low levels of parasitaemia ( 2 parasites $/ \mu$ l) can easily be detected as more blood is being used per sample $(55-65 \mu 1)$. There is no loss of parasites during the procedure.

\section{PCR (Polymerase Chain Reaction)}

Analysis of DNA by the polymerase chain reaction (PCR) can be a useful tool for diagnosis of malaria when the results of conventional techniques are negative, especially since PCR allows accurate species identification and can detect low level parasitaemia. PCR has a sensitivity and specificity of $100 \%$ with a detection limit of just one $P$. falciparum or three $P$. vivax parasites per micro litre of blood when compared with the gold standard. PCR has also been credited to have been able to detect mixed infections with ease in many studies (Parija, 2010). Several molecular methods, based on the amplification of DNA, like semi-nested multiplex malaria PCR (SnM-PCR) and real time quantitative PCR (qPCR) have been developed for the detection of malarial infections in humans (Morales et al., 2012).

Nested-PCR detects Plasmodium species DNA ( $P$. vivax, $P$. Falciparum and $P$. 
malariae) by amplification of the small subunit ribosomal ribonucleic acid (ssrRNA) genes using the primers and cycling parameters as described previously. This assay can detect the presence of one to ten parasites $/ \mu 1$ of blood.

Real-time PCR assays targeting Plasmodium falciparum lactate dehydrogenase (pfldh) gene may facilitate the identification of a high proportion of pregnant women with a $P$. falciparum parasitaemia below the threshold of microscopy (Rantala et al., 2010).

\section{Immunochromatographic Test}

This test is based on the capture of the parasite antigens from the peripheral blood using either monoclonal or polyclonal antibodies against the parasite antigen targets. This test can detect malaria antigen in a small amount of blood, usually $5-15 \mu 1$, by immunochromatographic assay (Wongsrichanalai et al., 2007).

RDTs (Rapid Diagnostic Tests) consist of nitrocellulose strips mostly embedded in plastic cassettes. When blood and buffer are applied, the red blood cells are lysed and the targeted antigen binds to the detecting mouse antibody which is conjugated to colloidal gold. This complex moves further along the nitrocellulose strip until the antigen binds to the capture antibody embedded as a transverse line on the nitrocellulose strip. As a result, the colloidal gold is concentrated on a small surface and becomes visible as a purple-red line. The non-bound conjugated antibodies move further along the strip until they are captured by goat anti-mouse antibodies, thereby generating the control line. Two-band RDTs consist of a control line and a $P$. falciparum specific test line which targets either histidine-rich protein-2 (HRP-2) or $P$. falciparum specific lactate dehydrogenase (Pf-pLDH). Three-band RDTs display three lines: a control line, a $P$. falciparum-specific line (detection of HRP-2 or Pf-pLDH) a third line detecting $P$. vivax (by a $P$. vivaxspecific pLDH, Pv-pLDH) or an antigen common to all four species, either aldolase or pan-Plasmodium-specific pLDH (pan$\mathrm{pLDH})$.

Fig.1 The incidence rate of Malaria worldwide

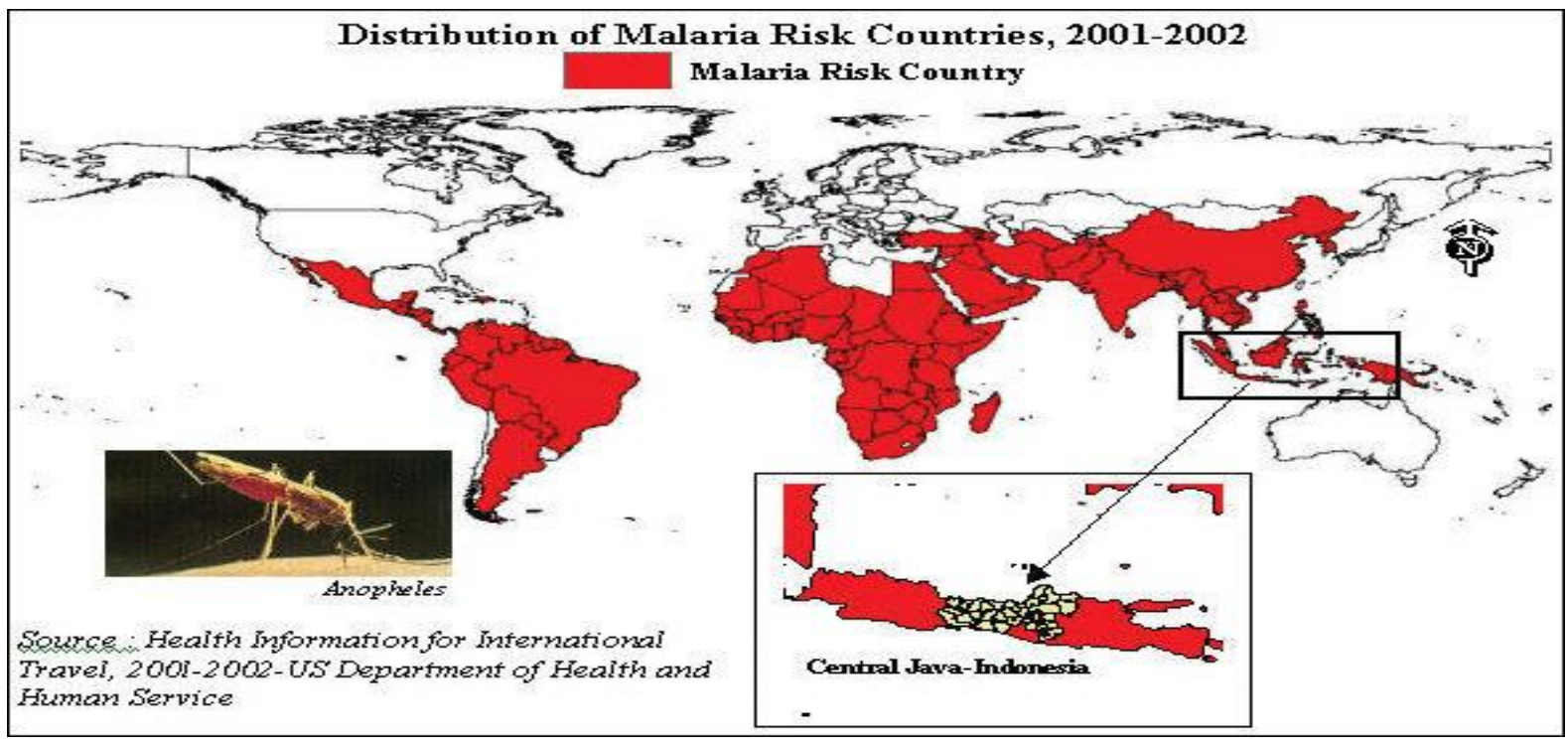


Fig.2 Positive Blood Smear under Fluorescent Microscope

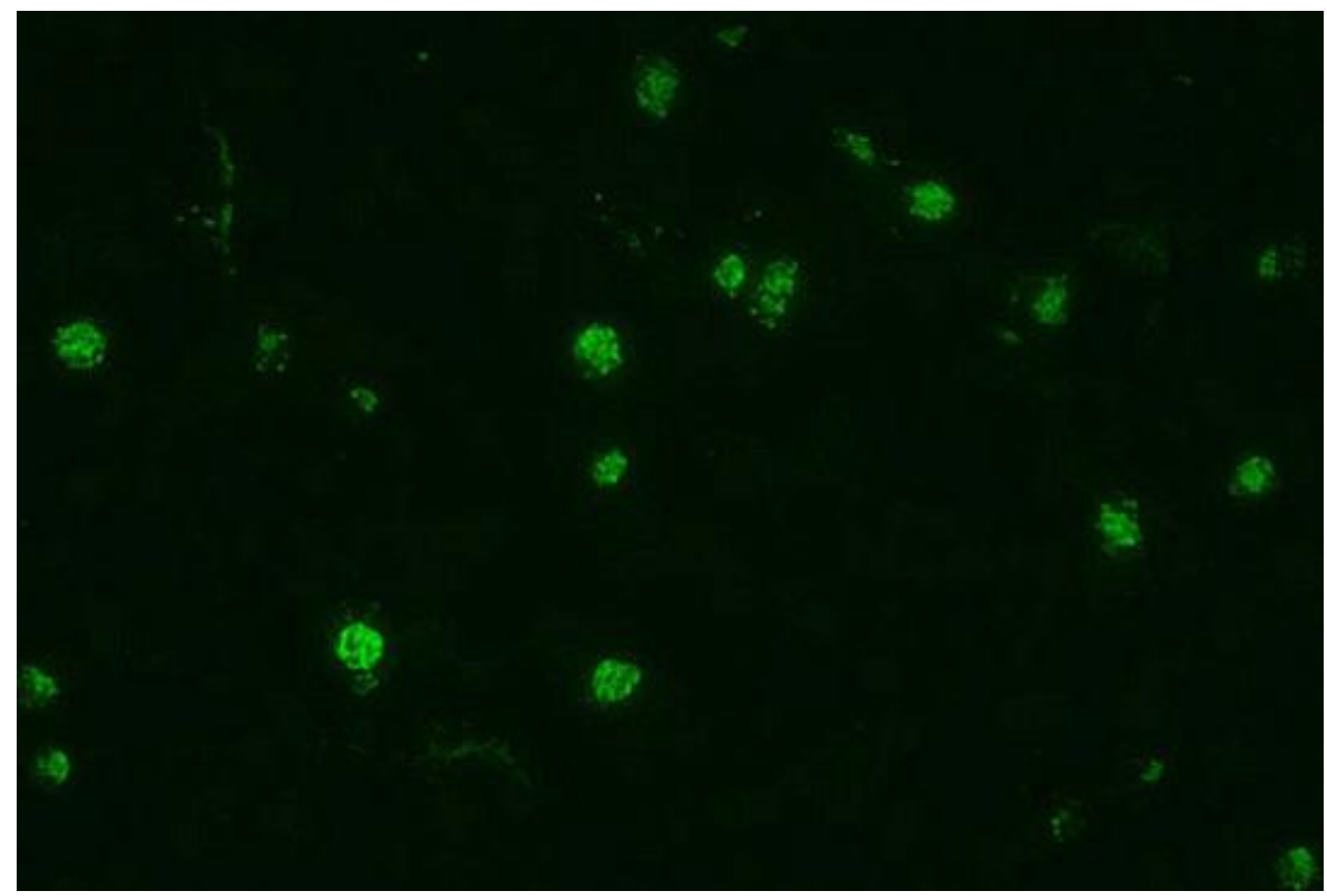

Fig.3 Interpretation of RDTs

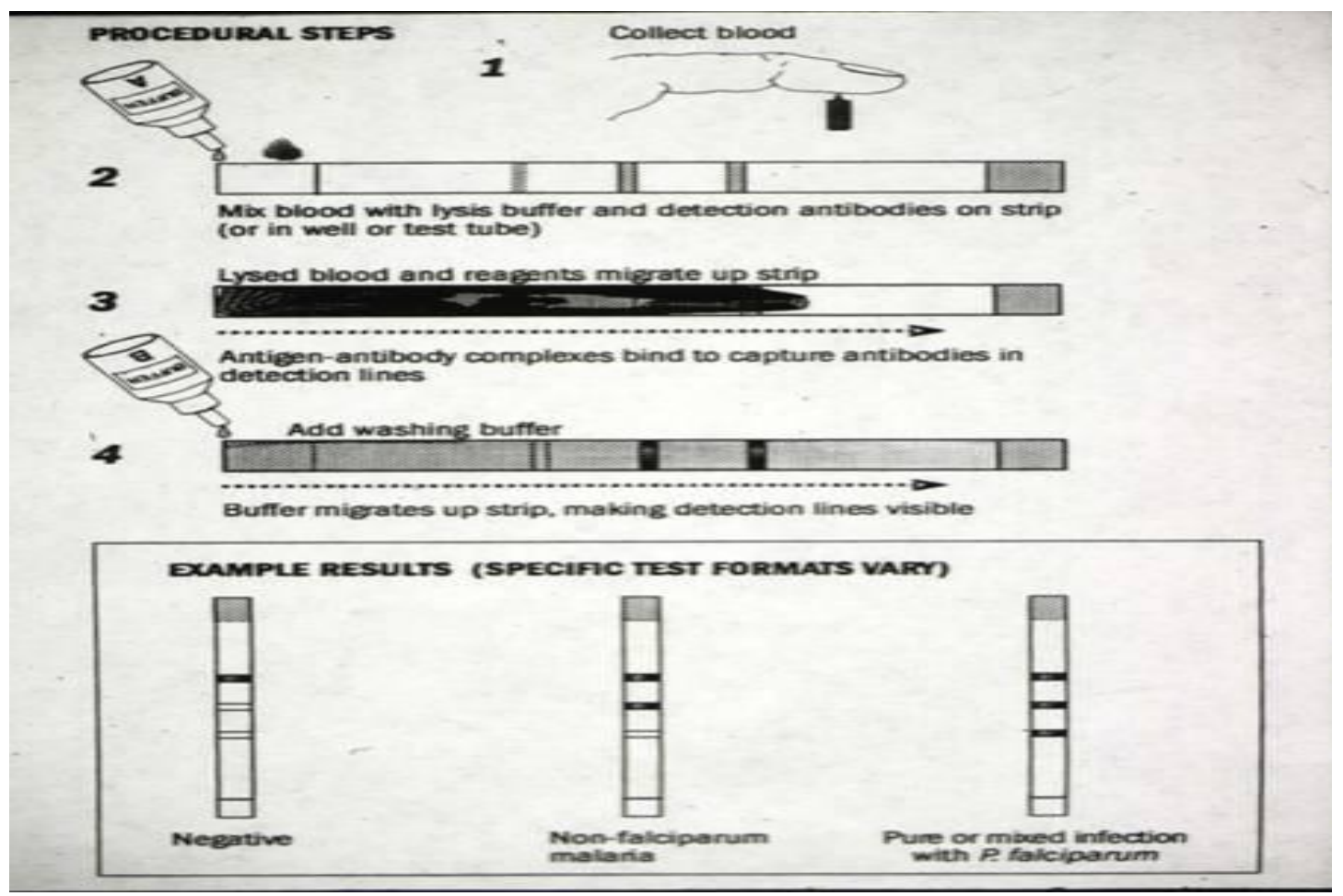




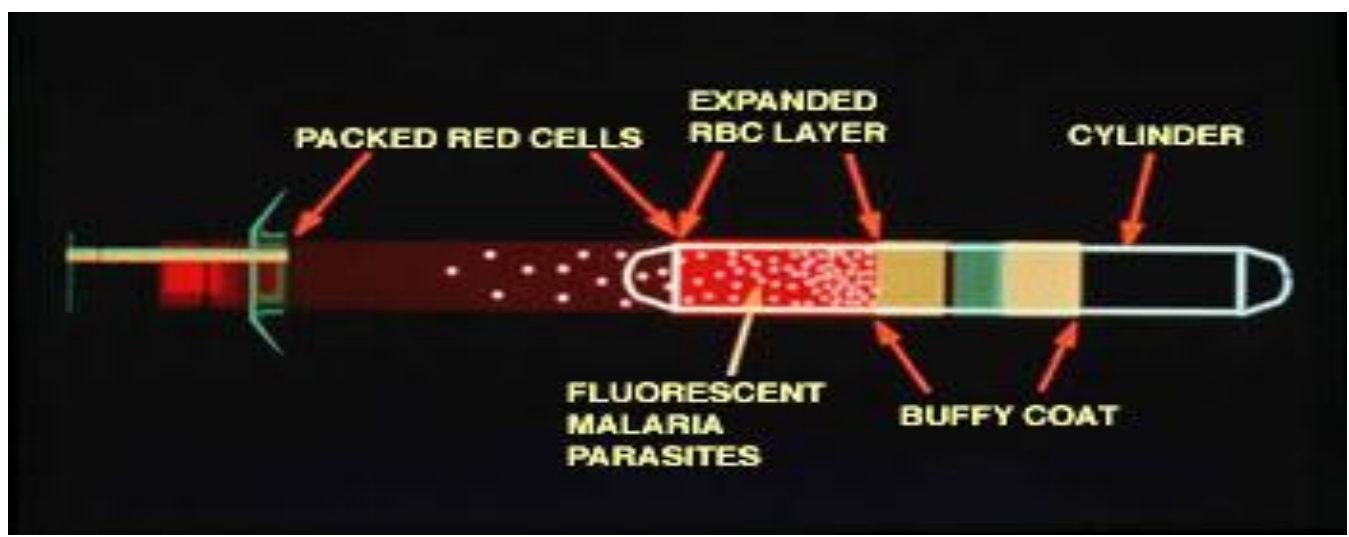

\section{Laser Desorption Mass Spectrometry (LDMS)}

This method is based on the detection of heme in hemozoin $(\mathrm{Hz})$, the crystalline substance accumulated within malaria parasites during their intraerythrocytic growth stage The LDMS test requires no consumables other than a lancet and a container for blood collection. Blood is diluted in water, deposited onto a metal slide, air dried, and then inserted into the mass spectrometer for analysis. $\mathrm{Hz}$ heme is identified from the pattern of hememolecular-structure-specific peaks. A correlation filter $(\mathrm{CF})$ algorithm is used to score local mass spectra for the presence of $\mathrm{Hz}$ heme during spatial scanning of the laser beam across the sample (Feldman et al., 2010).

In conclusion, we concluded that the advance methods for detection of Malaria has many advantages over old methods. RDTs kits are most commonly used in diagnosis of malaria as these are cost effective, easily available, very fast results and no trained technician needed. Serological tests are helpful for epidemiological surveys, but not apposite for the diagnosis of acute malaria. Molecular-biological techniques are suitable for research laboratories; they can be used to spot the development of drug-resistance, are useful for identification of species, and also to quantify parasite density in blood of patient having low parasitemia The level of malaria endemicity, the urgency of diagnosis, the understanding of the physician, the efficacy of healthcare workers, and financial resources, are all factors influencing the choice of malariadiagnostic method.

\section{References}

Alias A, Afifi S, Zuraidha R et al. Malaria diagnosis by quantitative buffy coat technique. Med J Malaysia. 1996; 51(2): 227-31.

Azikiwe, C.A., C.C. Ifezulike, I.M. Siminialayi. et al. 2012. A comparative laboratory diagnosis of malaria: microscopy versus rapid diagnostic test kits. Asian Pacific J. Tropical Biomed., 307-310.

Centers for Disease Control and Prevention (Internet). Atlanta, USA: Maleria (Updated 2012 august9). Available from: http://www.cdc.gov/MALARIA/

Feldman A, Lin J, Murphy S, et al. Rapid Detection of Malaria Parasites. Johns Hopkins Apl Technical Digest. 2010: 28(3): 232-33.

Hassan, H.S., Haggaz, D.A., Elhassan, M.E., et al. 2011. Fluorescence microscope 
$\left(\right.$ Cyscope $\left.^{\circledR}\right)$ for malaria diagnosis in pregnant women in Medani Hospital, Sudan. Diagnostic Pathol., 24(6): 88.

Heutmekers M, Gillet P, Maltha J, et al. Evaluation of the rapid diagnostic test CareStart pLDH Malaria (Pf$\mathrm{pLDH} / \mathrm{pan}-\mathrm{pLDH}$ ) for the diagnosis of malaria in a reference setting. Malaria Journal. 2012 June 18: 11:204.

Kakkilaya, B.S. 2003. Rapid Diagnosis of Malaria, laboratory medicines, 8(34): 602-8.

Kantele, A., Jokiranta, S. 2010. Plasmodium knowlesi--the fifth species causing human malaria. Duodecim. 2010;126(4):427-34. Available from: http://www.ncbi.nlm.nih.gov/pubmed/ 20486493? report=docsum

Kuadeepa, V., Sukesh. 2012. Quantitative Buffy Coat (Qbc) Test and Other Diagnostic Techniques for Diagnosing Malaria: Review of Literature. National J. Med. Res., 2(3): 386-88.

Maleria Rapid Diagnostics Test Performance (Internet). Geneva: World Health Organization; 2010. Available from: http://www.who.int/tdr/publications/d ocuments/rdt3.pdf

Morales, M., Lehmann, R., Quispe, M., et al. 2012. Microscopy and molecular biology for the diagnosis and evaluation of malaria in a hospital in a rural area of Ethiopia. Malaria J., 11: 199.

Parija, S.C. 2010. PCR for diagnosis of malaria. Indian J. Med. Res., 132: pp 9-10.

Perkins, J.D., Were, T., Davenport, C.G., et al. 2011. Int. J. Biol. Sci., 7(9): 14271442.

Rantala, A.M., Taylor, S., Trottman, P., et al. 2010. Comparison of real-time PCR and microscopy for malaria parasite detection in Malawian pregnant women. Maleria J., 9: 269.

Salmani M, Mindolli P, Peerapur B. Comparative study of peripharal blood smear, QBC and antigen detection in Malaria diagnosis. Journal of Clinical and Diagnostic Research. 2011;5(5): 967-969.

Wongsrichanalai, C., Barcus, M., Muth, S., et al. 2007. A Review of Malaria Diagnostic Tools: Microscopy and Rapid Diagnostic Test (RDT). Am. J. Trop. Med. Hyg., 77 (Suppl. 6), 2007: pp. 119-127.

Zakeri, S., Kakar, Q., Ghasemi, F., et al. 2010. Detection of mixed Plasmodium falciparum \& P. vivax infections by nested-PCR in Pakistan, Iran \& Afghanistan. Indian J. Med. Res., 132: pp 31-35.

\section{How to cite this article:}

Rajdeep Paul, Shyam Sundar Bera and Sumi Nongrum. 2016. A Review of Advance Techniques in Diagnosis of Malaria. Int.J.Curr.Microbiol.App.Sci. 5(11): 631-636. doi: http://dx.doi.org/10.20546/ijcmas.2016.511.074 